\title{
Reflexions sobre els ilergets a partir d'un fragment de cràter àtic de figures roges trobat al Tossal de la Sal (Juneda, les Garrigues, Lleida)
}

\author{
Reflections on the Ilergetes based on an Attic \\ red-figure krater fragment discovered at Tossal de \\ la Sal (Juneda, les Garrigues, Lleida)
}

Es presenta la troballa casual d'un fragment de cràter àtic de figures roges en un jaciment ilerget. El seu interès és doble: d'una banda, completa el repertori iconogràfic del Grup del Pintor de Telos afegint-hi una nova escena relacionada amb el banquet. En segon lloc, permet discutir sobre aquest tipus de béns de prestigi a l'occident català. La seva troballa en un indret que no sembla ser de primer ordre qüestiona la tradicional associació de vasos de luxe amb centres rectors del territori. Aquesta reflexió permet albirar un paper més actiu dels centres secundaris en la competició social regional de la qual feia part l'exhibició d'importacions.

Paraules clau: ibers, ilergets, cràter àtic de figures roges, Grup del Pintor de Telos, béns de prestigi.
This paper presents the chance find of a fragment of an Attic red-figure Krater at an Ilergete site. Its interest is twofold. Firstly it completes the iconographic repertoire of the Telos Painter Group by adding a new banquet scene. Secondly, it serves to initiate discussion about this type of prestige good in Western Catalonia. Its discovery in a location that seems not to be of prime importance challenges the traditional association of luxury goods with centres of power that govern a territory. This case reveals a more active role of secondary centres taking part in the regional social competition for imported goods.

Keywords: Iberians, Ilergetes, Attic red-figure krater, Telos Painter Group, prestige goods. 
R. Graells i I. Garcés, Reflexions sobre els ilergets a partir d'un fragment de cràter àtic de figures roges trobat al Tossal de la Sal



Figura 1. Situació del Tossal de la Sal. Dibuix: I. Garcés.

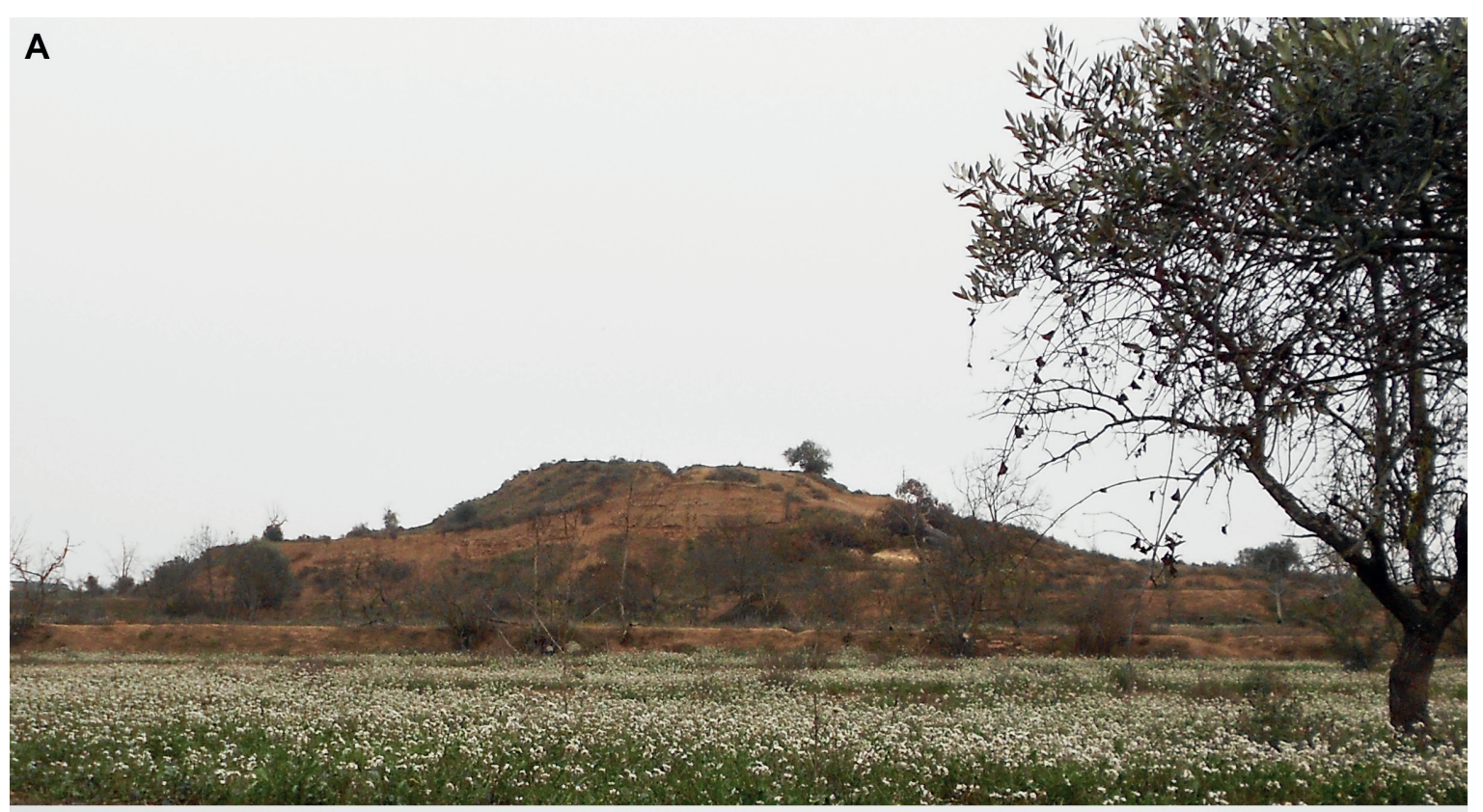

B

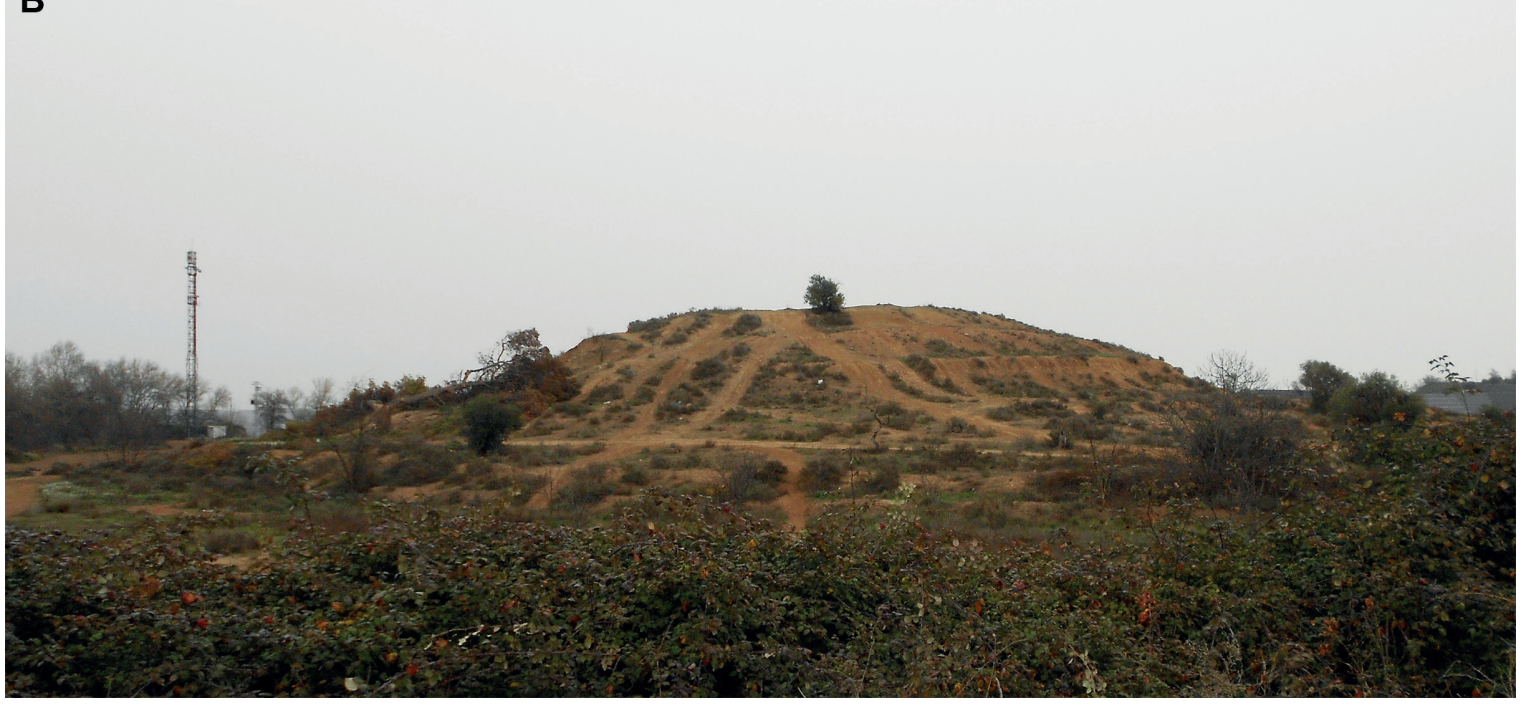

Figura 2. Vistes del Tossal de la Sal (Juneda). A. Vista des del nord; B. Vista des del sud-oest. Fotografies: R. Graells. 

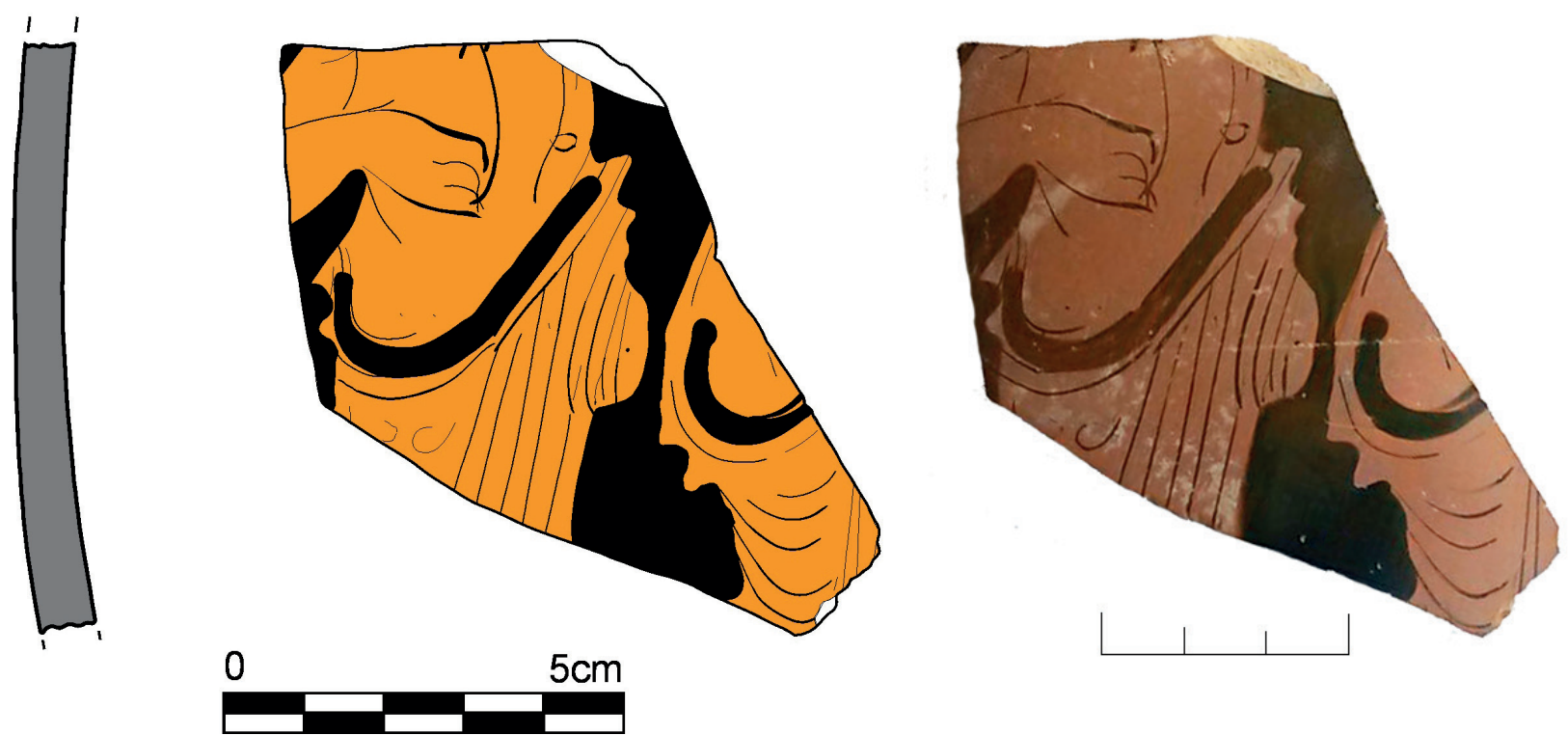

Figura 3. Fotografia i dibuix del fragment de cràter de figures roges atribuït al Grup del Pintor de Telos. Dibuix: I. Garcés.

\section{Introducció}

La presència d'importacions ha estat un dels elements que millor han guiat els investigadors per plantejar interpretacions i distingir graus i nivells de riquesa, estatus i jerarquia. Entre aquestes importacions la ceràmica àtica, i més concretament la figurada amb la tècnica de figures roges, ha jugat un paper considerable durant la protohistòria. Cal dir que aquest repertori, a l'interior català, no ha estat encara analitzat de manera sistemàtica $\mathrm{i}$ únicament es disposa del dossier complet de troballes del Molí d'Espígol (Tornabous, Urgell) (Cura 2000: passim; 2006: 75-78) i d'un recull de troballes disperses de disset jaciments. Falten encara per editar els destacats conjunts dels jaciments dels Vilars (Arbeca, les Garrigues) o Sikarra (Prats de Rei, Anoia) (Principal 2000: passim). ${ }^{1}$ Tot i que el catàleg de la ceràmica àtica a l'interior català és limitat en nombre, és ben possible que, com bé va indicar J. Principal, sigui a causa del dèficit d'excavacions realitzades (Principal 2000: 217). Per això l'adjunció de noves troballes no és una menudesa, ans al contrari, ajuda a completar el mapa de distribució i aporta a la recerca sobre el món ilerget noves preguntes i problemes.

Les pàgines que segueixen presenten la troballa casual d'un fragment de cràter àtic de figures roges al terme municipal de Juneda (les Garrigues) ${ }^{2}$ (figura 1), en un jaciment situat al Tossal de la Sal

1. Una síntesi en el Seminari titulat "Seminari sobre ceràmica àtica. Figures roges i vernís negre. Confrontació dels materials apareguts a Vilars (Arbeca) i Sikarra (els Prats de Rei)" (<http:// www.vilars.cat/Activitats/Noticies-des-de-la-Fortalesa/Seminarisobre-ceramica-atica.-Figures-roges-i-vernis-negre.-Confrontaciodels-materials-apareguts-Vilars-Arbeca-i-Sikarra-els-Prats-de-Rei> consultat el 31 de desembre de 2015); i en el catàleg de l'exposició "La Fortalesa dels Vilars d'Arbeca. Terra, Aigua i Poder al món iber" (Museu de Lleida: Diocesà i Comarcal, 19 maig - 31 juliol 2016).

2. Donat al Museu de Lleida Diocesà i Comarcal el 5 de gener de 2016 (Acta L104E30 1/16). (coord. UTM: X 319.520 Y 4.601.678) que no serà objecte de cap altre comentari que la seva descripció i ubicació geogràfica. El tossal, situat al marge dret del riu Femosa, ocupa les cotes entre 280 i $266 \mathrm{~m}$ snm, i es troba avui molt alterat respecte la seva fesomia original a causa d'abancalaments i de la pràctica de motocròs (figura 2). Aquest jaciment és, a efectes pràctics, inèdit en la bibliografia, tot $i$ que ja va ser registrat a la Carta Arqueològica de les Garrigues que efectuà el Servei d'Arqueologia de la Generalitat en novembre de 1984, data en la qual es van fer algunes fotografies que mostren el deteriorament d'un tossal no gaire ampli; les troballes en superfície que es coneixen abasten l'edat del bronze, el període ibèric, la fase romano-republicana i alguna troballa romana imperial.

L'objectiu d'aquest treball és donar a conèixer la troballa, contextualitzar-la en les dinàmiques comercials de vasos de prestigi mediterranis a l'interior de Catalunya i, a l'últim, posar sobre la taula la necessitat d'un estudi de conjunt sobre les importacions gregues a l'interior de Catalunya.

\section{Descripció del fragment}

Fragment de la cara A d'un cràter amb representació de dos personatges masculins dempeus orientats a dreta, amb el tors en part nu i en part cobert amb un himátion lligat a la cintura que deixa la part superior doblegada tot mostrant una sanefa negra. La primera figura presenta el braç dret plegat sobre el cos i la mà tancada, feta de manera barroera mitjançant traços ràpids que dibuixen només tres dits gruixuts; la segona figura es reconeix tot i estar precàriament conservada, la qual cosa no impedeix identificar el seu gènere a partir de la seva vestimenta, similar a la del primer personatge (figura 3).

Dimensions: $45 \mathrm{~mm}$ d'ample per $29 \mathrm{~mm}$ d'altura. MLDC N. Inv. 4433.

Segons indicacions del descobridor es van recuperar dos fragments més de la mateixa peça, de dimensions lleugerament superiors però amb decoració diferent, 
coberts amb vernís negre i decorats amb motius en reserva (vermell) corresponents a sanefes o elements vegetals, mal conservats. A causa de la impossibilitat d'identificar-hi cap figura no van ser conservats. La possibilitat que els tres fragments formessin part d'un mateix vas no es pot descartar.

\section{Atribució}

Tot i la fragmentació i parcialitat de les figures representades, a partir de la posició del braç, del detall de la mà i de la manera com es defineix el cos del personatge esquerre (mugró i línia mitjana del cos), el fragment pot relacionar-se amb un pintor del Grup de Telos (sobre aquest grup vid. Domínguez Monedero, Sánchez 2001: 427-432). Només una característica d'aquest grup sembla distanciar el present exemplar: la sanefa negra de l'himátion i la manera com està definida. La cronologia avui acceptada per aquest grup és de primer quart del segle IV $\mathrm{aC}$, tot $\mathrm{i}$ que per a la seva recepció a la Península s'accepta un lapse de temps més dilatat que abasta tota la primera meitat del segle Iv aC (Domínguez Monedero, Sánchez 2001: 427-432; Rotroff 2005: passim; Gil 2010: 14-15).

Alguns detalls anatòmics, com el braç en angle plegat sobre el pit però amb el colze cap enfora, són característics de la sèrie, ${ }^{3}$ així com la mà, normalment feta de manera ràpida i esquemàtica, representada tancada i resolta només amb tres dits, normalment molt gruixuts. Aquesta característica també s'observa sobre cràters del Retorted Painter, però en aquest cas els detalls anatòmics s'allunyen dels del fragment en estudi, així com la naturalesa dels personatges, normalment sàtirs o silens. Els pectorals es defineixen per la línia de contorn i per una lleu curvatura de la separació entre ells, els mugrons es realitzen de forma desacurada com a cercles més o menys regulars, mentre que el detall abdominal no es té en consideració.

Respecte al vestit, les sanefes negres de la vora superior de l'himátion corresponen a senzilles línies gruixudes disposades de manera seqüenciada $i$ en forma d'U, en canvi en la majoria de representacions de figures amb l'himatió caigut del Grup de Telos repeteixen sempre una forma en S horitzontal. ${ }^{4} \mathrm{Amb}$ aquest detall, l'artista dóna plasticitat i cert dinamisme a la caiguda del teixit, però lluny d'un detall de qualitat es tracta d'un recurs efectiu que suavitza la manca de volums i tridimensionalitat de la pintura. Les línies dels plecs del teixit són poc expressives en el nostre fragment, verticals en una meitat del teixit i en l'altra com una seqüència de línies horitzontals corbades. En el conjunt del Grup de Telos es presenten dues sèries de línies paral-leles a la curvatura de la sanefa gruixuda però dividides per una línia vertical. Les diferències entre les dues formes de

3. Beazley Archive. <http://beazley.ox.ac.uk>, Nr. 260067 (Atenes, Pnyx, P231 i 274), 260068 (Copenhagen, National Museum, CHRVIII291-1), 260069 (Oxford, Ashmolean Museum, 1956.372), 260082 (BM F80) o 260095 (Atenes, NM, 13899).

4. Beazley Archive: Nr. 260063 (Oxford, Ashmolean Museum), 260062 (Cambridge, Museum of Classical Archaeology), 260067 (Atenes, Pnyx, P231 i 274), 260068 (Copenhagen, National Museum, CHRVIII291-1) o 260069 (Oxford, Ashmolean Museum, 1956.372). presentar aquest teixit responen, però, a una lògica correcta per part de l'artista: la majoria de les figures que formen el catàleg del Grup de Telos corresponen a figures de personatges asseguts, fet que contrasta amb els dos de la representació que ens ocupa, on es presenten dempeus.

\section{Interpretació de l'escena}

Entre les representacions atribuïdes al Grup de Telos no es coneix cap representació amb dues figures masculines dempeus amb els torsos nus en processó o disposades en fila, indiferent si cap a la dreta o l'esquerra. A més, l'absència d'atributs dificulta la identificació concreta de l'escena. Tot i així, altres detalls permeten situar-la en un marc iconogràfic genèric. La representació de dos personatges masculins orientats cap a la dreta i dempeus dificulta la interpretació com a una escena dionisíaca típica, ja que presentaria la divinitat asseguda juntament amb altres personatges típics del seu seguici, com sàtirs i mènades, normalment ballant, com en els dos exemplars del Grup de Telos que han aparegut a Empúries (Miró 2006: 222 i fig. 579, 2945 i 2946). El detall dels torsos parcialment nus s'oposa també a les escenes de les cares B, on normalment es representa un grup de tres personatges masculins coberts completament pel teixit. Lúnic context on es documenten personatges masculins amb el tors com el cas que ens ocupa és en escenes de banquet, però en aquells contexts apareixen estirats sobre klinai i no dempeus.

Sembla, en qualsevol cas, que els dos personatges del fragment de Juneda representin un escena nova dins el repertori del Grup de Telos (com a mínim per a la península Ibèrica), tot i que previsiblement emmarcada en la iconografia pròpia del discurs homoeròtic del banquet grec però no relativa al kómos. La disposició de les dues figures les presenta de manera calmada però no seriosa, com indica el tors nu, combinació coherent amb la lògica iconogràfica d'algunes representacions dionisíaques de primer quart del segle IV aC on Dionís, al centre, rep els participants del seu festeig, normalment presentats en parelles orientades en direcció convergent cap a la divinitat. ${ }^{5}$ Allò que queda clar és la impossibilitat de reconstruir completament l'escena i menys encara comprendre com era percebuda pels seus propietaris ibers.

\section{La ceràmica àtica de figures roges a la plana lleidatana}

La plana occidental catalana és un territori que ha estat densament poblat al llarg de la història. La carta arqueològica és plena de punts que han reportat materials de diferents moments i cultures, però aquest coneixement general que es té no permet, en molts casos, aprofundir sobre la distribució de materials més o menys emmarcats en una mateixa fase cronològica sense poder avaluar ni les dimensions ni la veritable funció dels diferents jaciments. La recerca s'ha centrat,

5. Vid. Pintor de Meleagre, Beazley Archive, Nr. 218022 (col.l privada) o Pintor de Wurzburg 523, Beazley Archive, Nr. 218021 (BM 1772.3-20.201). 
necessàriament, en uns jaciments concrets, que són els que concentren les dades per a la construcció del discurs històric.

Per a la fase ibèrica, el coneixement que es té de la cultura ilergeta sembla avui consistent, si bé la ciutat que donaria nom a l'ètnia i al territori no es coneix i sols uns quants hàbitats han estat explorats o continuen en excavació. La fase millor coneguda sembla ser, si atenem a les publicacions de què es disposa, el segle III $\mathrm{aC}$, però la presència de materials del segle Iv aC i anteriors sembla consistent i suficient per situar la cultura ilergeta com una societat en grau d'estructurar el territori, jerarquitzar-lo i relacionar-lo amb altres territoris i mercats ben coneguts a partir dels estudis d'altres àrees del nord-est peninsular. Ja per a les primeres fases de la cultura ibèrica, en el segle vi aC, s'observa una relació amb territoris geogràficament situats fora de la plana occidental catalana mitjançant vies naturals, entre la Conca de Barberà i la zona d'Arbeca, per exemple (Graells 2008: 40). Lús de vies de comunicació naturals sembla no haver patit mai interrupcions sinó que, al contrari, semblen haver jugat un rol particular per estructurar el territori i poblament, tal com podria definir la via del riu Corb o la de la Femosa. Aquesta estructuració del territori pot definir dos models de poblament complementaris, en altura $\mathrm{i}$ en pla, resta conèixer més jaciments per determinar si una posició topogràfica diferent implica també un rol divers que les estructures, però sobretot els tipus de materials recuperats, definiran.

A partir de les dades publicades s'observa com les ceràmiques de figures roges de jaciments lleidatans es poden atribuir al Pintor del Tirs Negre, al grup de Viena 116 i possiblement també al Pintor de Toya. Els motius representats són els freqüents a la Península durant aquest moment, és a dir, escenes seriades amb personatges coberts amb mantell i representacions del cicle dionisíac. D’altra banda, les formes més comunes són els vasos per a beure i de tocador (cosmètics i perfums, com lékythoi o lekànides). Són menys freqüents els cràters que, com va indicar J. Principal amb el material a disposició en el moment del seu estudi, es concentrarien de manera privilegiada en centres singulars com a marcadors d'estatus, nobles o de luxe (Principal 2000: 223), afirmació que trobaria confirmació amb la presència a la fortalesa dels Vilars (Arbeca, les Garrigues) (Vid. nota 4) i a l'oppidum de Molí d'Espígol (Tornabous, Urgell) (Cura 2000; 2006).

En qualsevol cas, si se segueix l'únic dossier publicat d'un d'aquests jaciments, el de Molí d'Espígol, els percentatges presentats per M. Cura mostren una presència de vasos de figures roges excepcional (Cura 2000: 226-227, fig. 2; 2006: 83-84, fig. 33), possiblement corresponent a cinquanta peces (Cura 2000: 227; 2006: 75-78 i 83, fig. 33): 14 kylikes, 10 lekànides, 5 skyphoi, 3 kántharoi, 1 possible oinokhóe, 1 pelíke, 1 nansa de pelike, 2 lékythoi, 1 fragment d'hydría i 12 cràters de campana (Cura 2006: 75-76, làms. 84.2, 6 i 8; 86.3, 5 i 11-12; 87.1, 7 i 10). Entre aquests cràters, com a comparació per a l'exemplar de Juneda, destaca la presència de figures masculines vestides amb himátion -un completament cobert (Cura 2006: 84.2) i el segon dansant (Cura 2006: 86.3) — i un fragment amb un personatge vestit com a escita (Cura 2006: 86.5). És destacable d'aquests cràters la seva fragmentació, fet que va impedir una identificació estilística amb l'excepció del fragment amb representació d'escita, atribuït a l'estil de Kertx (Cura 2006: 75). La resta de peces s'han relacionat amb el Pintor de Toya (Gracia 1986: 11; Cura 2006: 75, làm. 87.10) i amb produccions lleugerament posteriors a les del Pintor del Tirs Negre (Cura 2006: 75).

El gruix del dossier de figures vermelles de Tornabous es data al segon quart del segle Iv aC (Cura 2000: 227) fet que és rellevant si considerem que la majoria dels vasos destinats al consum del vi trobats al jaciment corresponen a peces de figures roges (Cura 2000: 229).

La troballa del fragment de cràter de Juneda resulta doncs del màxim interès per a la comprensió dels sistemes de distribució i acumulació dels vasos de prestigi entre el poblament lleidatà, ja que si es compleix la relació entre presència d'aquest tipus de vasos exclusivament en jaciments rellevants per a l'estructuració del territori ens trobaríem davant d'un jaciment a tenir en compte per a la recerca; la seva posició en anàlisis de distribució, vies de comunicació i relacions en la vall de la Femosa s'hauria de considerar de manera important, mentre que si no es compleix l'esmentada relació, posaria en qüestió una distribució organitzada i jerarquitzada de les importacions i, com a tal, implicaria proposar una estructuració tendencialment autònoma de les diferents poblacions del territori ibèric que, en definitiva, no distaria gaire de la idea d'una amalgama de petita noblesa local amb capacitat de competir socialment a escala regional. Aquest comportament ha regit nombroses societats ben estructurades des de l'antiguitat (Verger 2006) fins a l'actualitat tal com ho demostra, per exemple, l'organització afgana (Dawod 2004). No obstant això, en el cas ibèric, és convenient no perdre de vista com durant els primers cinquanta o seixanta anys del segle $\mathrm{IV} \mathrm{aC}$ les ceràmiques de figures roges esdevingueren accessibles no només a les elits sinó també a una part considerable de les poblacions ibèriques urbanes del Llevant, sud-est peninsular i alta Andalusia (García Cano, Gil 2009: 140). En el nord-est aquest equivalent urbà podrien haver-lo representat els centres poblacionals secundaris.

Qui sap si aquesta situació perdura fins a moments més avançats, quan la pressió sobre el territori tal vegada portaria alguns personatges a cercar fortuna en condició de mercenaris fora de les fronteres ibèriques (Graells 2011: passim; 2014: 176-177) o, ja durant la Segona Guerra Púnica, sota el lideratge dels cabdills ilergets Indíbil i Mandoni, en una situació de major cohesió política i cultural corresponent a la subfase ilergeta plena avançada (Garcés 2005: 425).

\section{Conclusions}

El fragment presentat formava part d'un cràter de campana àtica de figures roges amb una representació de comitiva, tal vegada del cercle dionisíac, feta per algun dels pintors de l'anomenat Grup de Telos, cronològicament situat en la primera meitat del segle IV aC. Si bé la representació es distancia de les característiques escenes documentades fins ara en el repertori àtic peninsular, el grup pictòric coincideix plenament amb els models que arriben a la península Ibèrica. La singularitat, però, és la seva forma i el context on es va recuperar. Un vas de prestigi com 
el cràter de campana en territori lleidatà, fins ara, corresponia a una part del binomi vas de luxe igual a centre de poder redistribuïdor d'importacions, de manera que la seva recuperació a Juneda, en un jaciment del qual no tenim major informació, posa sobre la taula la fiabilitat d'aquest binomi i obre la porta a fórmules més complexes de llegir la cultura material com a indicador d'estructures d'organització del territori, societat i comerç en les quals l'autonomia de petits centres pot prendre un paper destacat dins un discurs en el qual la competició social, mitjançant l'exhibició de símbols d'estatus, es presenta més polièdrica que allò que les tesis en vigor han defensat.

\section{Agraïments}

No es pot cloure aquesta notícia sense agrair al descobridor la donació del fragment al Museu de Lleida i haver indicat detalladament les condicions i lloc de la troballa. Un agraïment especial al professor Dr. J. M. García Cano (Universidad de Murcia), a la
Dra. D. Rodríguez (Beazley Archive Pottery Database, Oxford) i al professor Dr. P. Rouillard (UMR 7041, ArScAn, Maison Archéologie et Ethnologie, RenéGinouvès, Nanterre) per l'ajut en la identificació del pintor. També al Servei d'Arqueologia de la Generalitat de Catalunya per la consulta de la Carta Arqueològica de les Garrigues.

Raimon Graells i Fabregat Römisch-Germanisches-Zentralmuseum (RGZM) Ernst-Ludwig-Platz 2 D-55116 Mainz graells@rgzm.de

Ignasi Garcés Estallo

Universitat de Barcelona (UB) Carrer Montalegre 6 E-08001 Barcelona garces@ub.edu

\section{Bibliografia}

Cura, M. (2000). Cerámicas de estilo ático del siglo IV a.n.e. en el Molí d'Espígol (Tornabous, provincia de Lleida-Cataluña). A: La céramique attique du Ive siècle en Méditerranée occidentale. Actes du colloque international d'Arles 1995, Coll. CJB 19/Travaux CCJ 24 (Naples, 2000): 225-232.

Cura, M. (2006). El jaciment de Molí d'Espígol (Tornabous-Urgell). Excavacions arqueològiques 19871992. Monografies MAC-Barcelona, 7. Barcelona.

Dawod, H. (dir.) (2004). Tribus et pouvoirs en terre d'Islam. Armand Colin, Paris.

Domínguez Monedero, A.; Sánchez, C. (2001). Greek pottery from the Iberian Peninsula. Archaic and Classical Periods. Brill, Leiden-Boston-Köln.

GARCÉs, I. (2005). Ilergets i lacetans occidentals. Deu anys de recerques $\mathrm{i}$ algunes propostes de síntesi. A: XIII Col-loqui Internacional d'Arqueologia de Puigcerdà. Món Ibèric als Països Catalans (Puigcerdà, 2003). Institut d'Estudis Ceretans. Puigcerdà, vol. I: 411-439.

García CANO, J. M.; GIL, F. (2009). La cerámica ática de figuras rojas: talleres y comercio (siglo IV a.C.). El caso de Coimbra del Barranco Ancho (Jumilla, Murcia). Universidad de Murcia. Murcia.

GIL, F. (2010). Morfometría y cerámicas áticas del siglo IV a.C. Las cráteras de campana del Grupo de Telos. Tesi de màster inèdita. Múrcia.

Gracia, F. (1986). Las influencias mediterráneas y el momento de plena formación de la cultura ibérica en Cataluña. Las cerámicas áticas y de barniz negro del poblado ibérico del Molí d'Espígol - Tornabous, Urgell. Tesi doctoral inèdita. Universitat de Barcelona.
GRAELls, R. (2008). La necròpolis protohistòrica de Milmanda (Vimbodí, Conca de Barberà, Tarragona). Un exemple del món funerari català durant el trànsit entre els segles VII $i$ VI $a C$. Hic et nunc, 5. Institut Català d'Arqueologia Clàssica. Tarragona.

Graells, R. (2011). Mistophoroi ilergetes en el siglo IV aC: el ejemplo de las tumbas de caballo de la necrópolis de la Pedrera (Vallfogona de BalaguerTérmens, Catalunya, España). Jahrbuch-RGZM, 55, 2008: 81-158.

Graells, R. (2014). Mistophoroi ex Iberias. Una aproximación al mercenariado hispano a partir de las evidencias arqueológicas (s. VI - IV a.C.). Archeologia Nuova Serie 1. Osanna Edizioni. Venosa.

Miró, M. T. (2006). La ceràmica àtica de figures roges de la ciutat grega d'Emporion. Monografies emporitanes, 14. Barcelona.

Principal, J. (2000). Panorama de la vajilla ática durante el siglo IV a.C. en la Cataluña Occidental. A: La céramique attique du Ive siècle en Méditerranée occidentale. Actes du Colloque International d'Arles 1995, Coll. CJB 19/Travaux CCJ 24 (Naples, 2000): 217-224.

Rotroff, S. (2005). Four Centuries of Attenian Pottery. A: V. Stolba, L. Hannestad (eds.). Chronologies of the Black Sea Area in the period c. 400-100 BC. Black Sea Studies, 3 Aarhus: 11-30.

Verger, S. (2006). La grande tombe de Hochdorf, mise en scène funéraire d'un cursus honorum tribal hors pair. Siris, 7: 5-44. 